\title{
Defecto septal atrioventricular tipo Gerbode. Relato de una malformacion poco frecuente
}

\author{
Clara A Vazquez Antona* \\ Ivan Rivera Romero ** \\ Ricardo Pignatelli **
}

Correspondencia

Clara A Vázquez Antona

vazquezantona@gmail.com

Departamento de Ecocardiografia pediátrica. Instituto Nacional de Cardiología Ignacio Chávez, Ciudad de México, México

* Universidad Federal de Alagoas, Maceió, Brasil

** Section of Pediatric Cardiology, Department of Pediatrics, Baylor College of Medicine, Texas Children's Hospital, Houston, Texas, USA

Recibido: 09/09/2020

Aceptado: 18/10/2020

En línea: 31/12/2020

Citar como: Vázquez Antona, C. A. Defecto septal atrioventricular tipo Gerbode. Relato de una malformación poco frecuente (RETIC). 2020 (Dic); 3 (3): 56-59. doi: 10.37615/retic.v3n3a16

Cite this as: Vázquez Antona, C. A. Gerbode-type atrioventricular septal defect. Report of a rare malformation (RETIC). 2020 (Dic); 3 (3): 56-59. doi: 10.37615/ retic.v3n3a16.

\section{Palabras clave}

$\triangleright$ Defecto septal atriventicular

$\triangleright$ Defecto gerbode

$\triangleright$ Ecocardiografía

$\triangleright$ Ecocardiografía

tridimensional

\begin{tabular}{l} 
Keywords \\
\hline$\triangleright$ Atriventicular septal defect \\
$\triangleright$ Gerbode defect \\
$\triangleright$ Echocardiography \\
$\triangleright$ Three-dimensional \\
echocardiography \\
\hline
\end{tabular}

\section{Introducción}

Los defectos septales ventriculares continúan representando un reto diagnóstico, no solo por la definición de los detalles anatómicos y de repercusión hemodinámica que se requieren para decidir el tratamiento, sino porque aún existen diferentes clasificaciones que hace que a un mismo defecto se le den diferentes nombres de acuerdo a su localización en el septum interventricular y su relación con las válvulas cardiacas o estructuras anatómicas como la cresta supraventricular ${ }^{(1)}$. Uno de los mayores retos diagnósticos corresponde a la comunicación del ventrículo izquierdo (VI) con la aurícula derecha (AD) por un defecto del septum atrioventricular (SAV).

El tabique interventricular estructuralmente está constituido por dos porciones: muscular y membranosa. La muscular se divide en 3 regiones: de entrada trabecular y de salida. La inserción de la hoja septal de la tricúspide, más apicalizada que la mitral, divide al septum membranoso en una porción supravalvular o atrioventricular y una porción inferior o interventricular, (ver elipse en el Gráfico 1).

En ambas porciones se podría generar una comunicación de ventrículo izquierdo (VI) a la aurícula derecha (AD), la superior sería directa (flecha roja en el gráfico) la inferior podría ser transtricuspídea (flecha verde en el gráfico) por diversos mecanismos
La primera descripción de comunicación directa entre VI y AD se hizo en 1838 por Thruman J; posteriormente Perry, Burchell y Edwards resumieron las variaciones anatómicas del defecto. En 1958 Gerbode y cols. describen cinco casos de cortocircuito de VI a AD mediante tres diversos mecanismos, pero todos involucraban a la VT. Desde entonces se da el nombre de "defecto tipo Gerbode"(2).

Hasta la fecha no hay más de 120 casos reportados; si bien la etiología es congénita, recientemente se han reportado más casos adquiridos secundarios a cirugía valvular o cierre de defectos septales, endocarditis bacteriana o incluso desgarro del anillo tricúspideo cercano al septum membranoso, así como post traumáticos ${ }^{(3)}$.

Se han propuesto diversas clasificaciones de acuerdo a las relaciones anatómicas del defecto, principalmente con la valva septal tricúspide. Inicialmente fueron clasificados en dos tipos: los defectos directos que comunican el VI con AD a través del tabique membranoso en su porción atrioventricular, y los defectos indirectos que involucran un defecto septal ventricular con insuficiencia tricúspidea (IT). Esta terminología se modificó para describir la posición de la anomalía en relación con la VT, reconociendo los defectos del SAV como supravalvulares y los defectos entre los ventrículos como infravalvulares (Figura 1).

Posteriormente se incorporó un tercer tipo con ambos componentes: supravalvular e infravalvular, denominados intermedios ${ }^{(2)}$. En estas descripciones las alteraciones de la VT que frecuentemente acompañan a estos defectos son la 


\section{- Trukipedia \\ Truco 03}

perforación de la porción anterior de la valva septal, hendidura de la valva, ensanchamiento de la comisura anteroseptal y, con menos frecuencia malformación aneurismática de la valva que se superpone al defecto septal ventricular y que permite la comunicación entre el VI y AD y/o IT. Sin embargo, el verdadero defecto AV depende de la ausencia del SAV por lo que debe localizarse por encima del anillo tricuspideo comunicando en forma directa el VI con AD (flecha roja en el Gráfico 1). La inserción de la valva septal es la clave para diferenciar entre una comunicación interventricular perimembranosa con alteración de la VT de un defecto SAV.

\section{Evaluación con el ecocardiograma}

El ecocardiograma 2D y 3D es el método diagnóstico de elección para esta cardiopatía. El ecocardiograma transtorácico (ETT) es suficiente si existe una ventana transtorácica adecuada, de no ser así se recomienda complementar con ecocardiografia transesofágica.

Las claves para el diagnóstico son:

- Con Doppler color en proyecciones apical de 4 cámaras (Figura 1 y Vídeo 1), eje largo paraesternal de ventrículo derecho(Figura 2 y Vídeo 2) o eje corto paraesternal, algunas veces modificado (Figura 3 y Vídeo 3), es posible diferenciar el flujo correspondiente a la IT (flecha) del cortocircuito del defecto AV que comunica el VI con la AD (asterisco).

- Con Doppler pulsado y continuo se observa que al alinear correctamente el flujo de IT (este es de diferente velocidad, generalmente más baja (Figura 1 A flecha y 1B) que el flujo que se origina cercano al borde septal del anillo tricúspideo por el defecto AV y que generalmente tendrá una velocidad $>4 \mathrm{~m} / \mathrm{seg}$, ya que corresponde al gradiente entre la presión elevada del VI y el AD (Figura $1 \mathrm{~A}$ asterisco y $1 \mathrm{C}$ ). Este debe distinguirse de otras lesiones como aneurisma roto del seno de Valsalva a AD en donde además hay un componente diastólico del flujo.

- Las vistas de superficie desde los atrios que se logran con Eco 3D localizan el defecto en el SAV por arriba de la inserción de la valva septal de la tricúspide y con eco 3D color el cortocircuito (Figura 4 y Video 4).

- Por lo general no existe hipertrofia ventricular derecha y la presión media pulmonar calculada por insuficiencia pulmonar es normal. Puede existir dilatación de atrio y ventrículo derecho dependiendo del tamaño del defecto y su repercusión hemodinámica.

- No es común que se asocien a otros defectos, pero en el caso congénito aquí presentado existía además una comunicación interventricular perimembranosa en vías de cierre (Figura 5).

\section{Estudio por imagen}

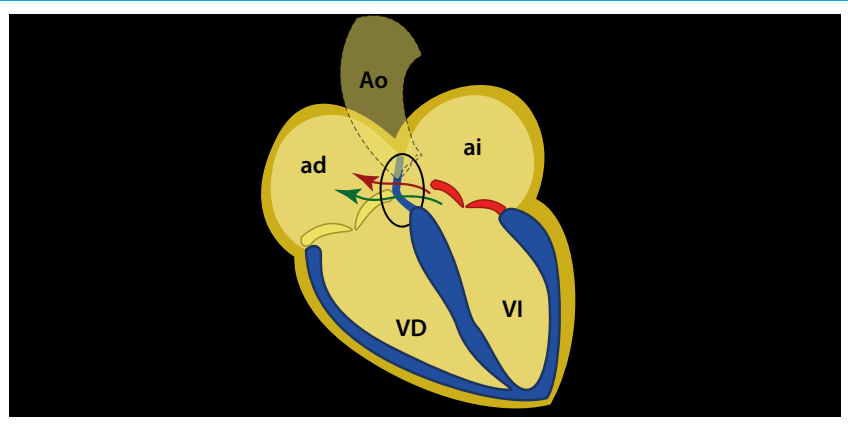

Gráfico 1. Esquema del septum membranoso, la división en porción superior e inferior que provoca la inserción apicalizada de la hoja septal de la tricúspide y posibles vías de comunicación de VI a AD

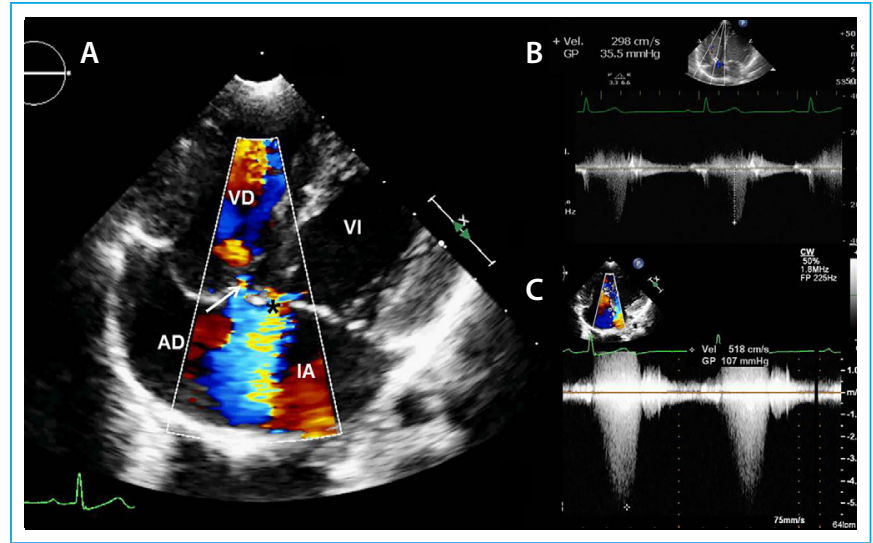

Figura 1. ETT 2D en apical de $4 \mathrm{C}$ en donde $\mathbf{A}$. muestra el cortocircuito de VI a AD por el defecto SAV (asterisco) y el flujo de IT (flecha). B. Muestra la velocidad de regurgitación tricúspidea de $2,98 \mathrm{~m} / \mathrm{seg}$ con la que se calcula la presión ventricular derecha de $40 \mathrm{mmHg}$ y la mayor velocidad del cortocircuito, que traduce el gradiente de VI a AD y que alcanza $5 \mathrm{~m}$ / seg $\mathbf{C}$.

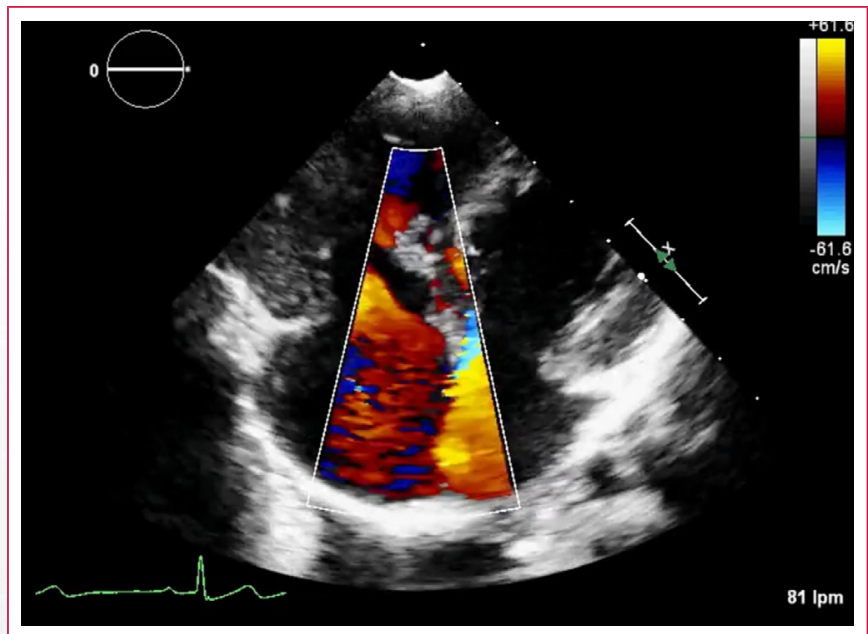

Vídeo 1. Video correspondiente a la Figura 1. Se muestra el cortocircuito de VI a AD por el defecto SAV y el flujo de IT

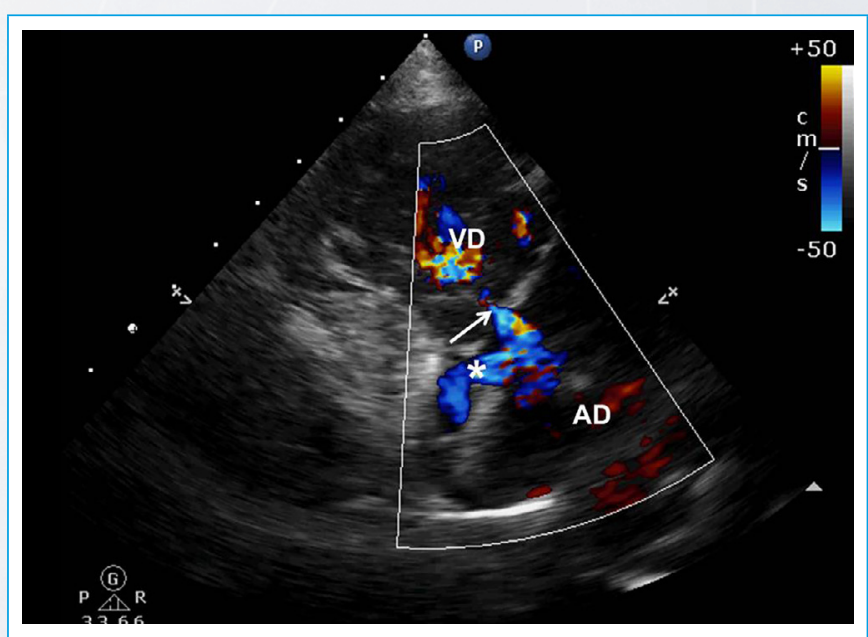

Figura 2. ETT en eje largo de VD en donde se observan ambos flujos, el de IT (flecha) y en el anillo lateral tricúspideo cercano al septum interventricular el flujo del cortocircuito por el defecto SAV (asterisco) 


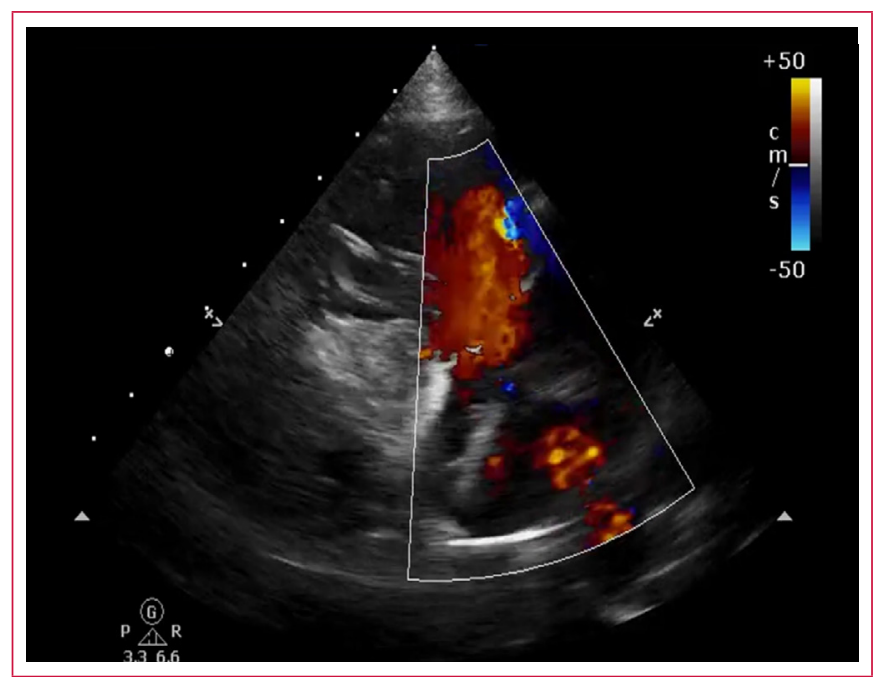

Vídeo 2. Video correspondiente a la Figura 2. Se muestran los flujos de IT y el flujo por el cortocircuito por el defecto SAV

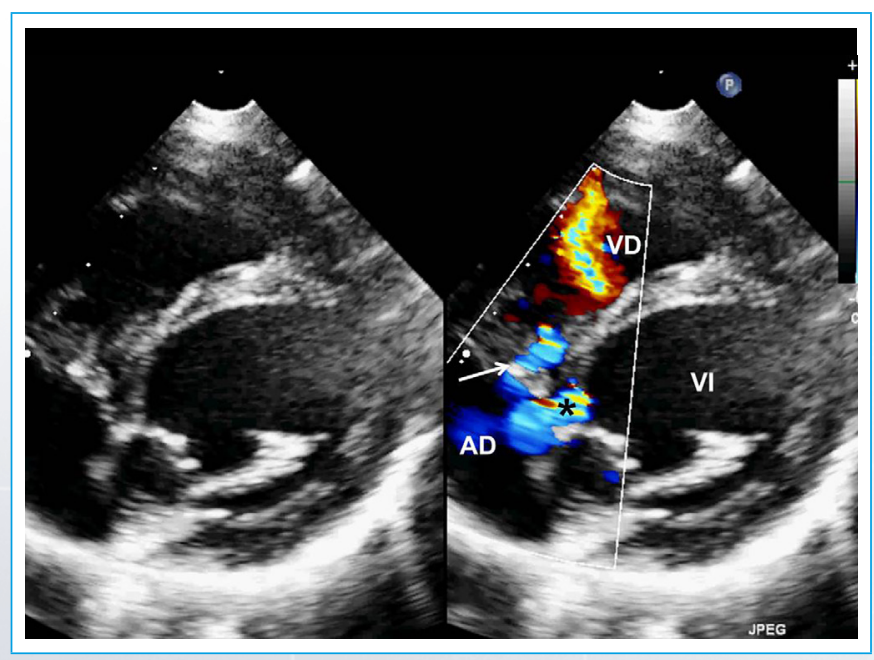

Figura 3. ETT Eco 2D en eje corto paraesternal modificado para mostrar el SAV y el cortocircuito de VI a AD (asterisco), diferenciándolo de la IT (flecha)

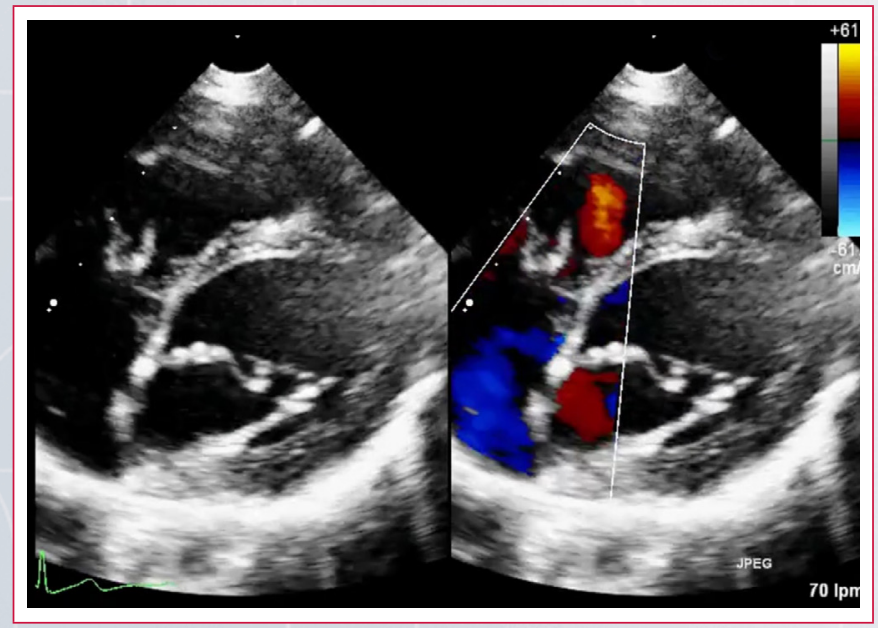

Vídeo 3. Video correspondiente a la Figura 3. La imagen en plano de eje corto modificado muestra el SAV y el cortocircuito de VA ia AD

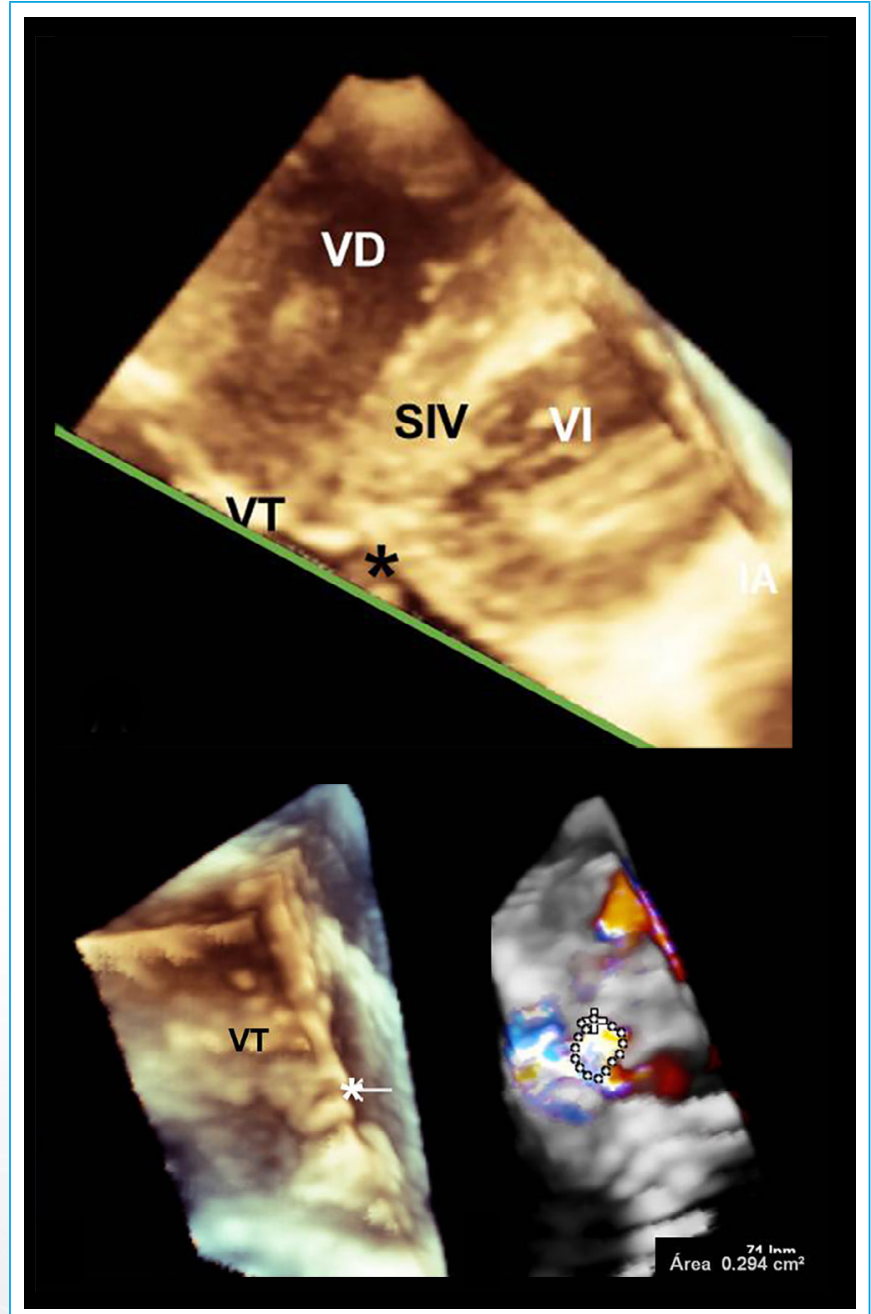

Figura 4. ETT 3D. A. la línea verde corresponde al plano de corte a nivel del anillo tricuspideo para mostrar la vista de superficie desde los atrios y definir el defecto SAV (asterisco)

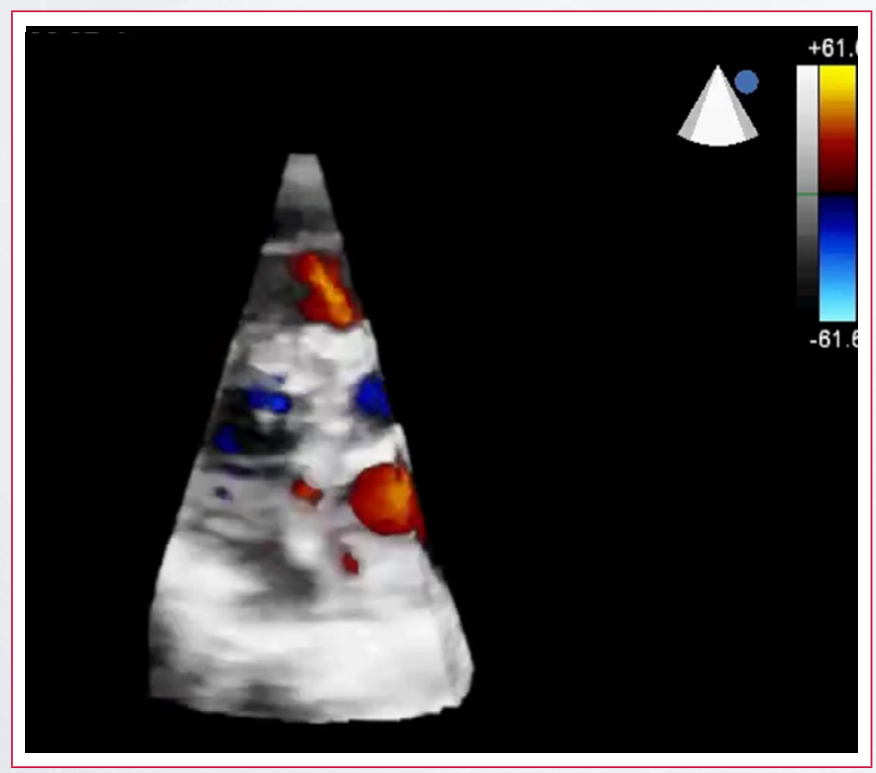

Vídeo 4. Eje corto 3D, de observa el defecto y el flujo a través de él 


\section{- Trukipedia Truco 03}

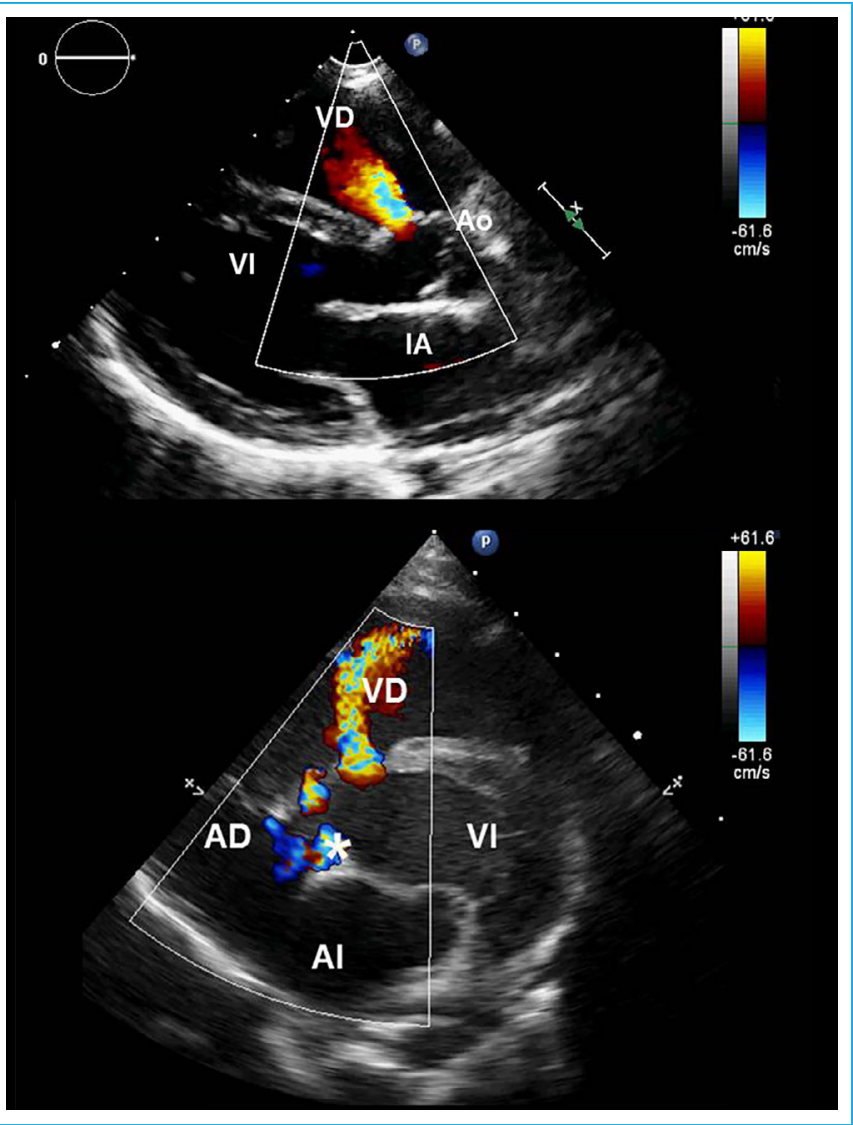

Figura 5. Imágenes ecocardiográficas paraesternales, se observa una comunicación interventricular perimembranosa asociada en vías de cierre, el asterisco muestra flujo en el defecto de VI a AD

\section{Ideas para recordar}

- El verdadero defecto AV depende de la ausencia del septo atrioventricular, por lo que debe localizarse por encima del anillo tricúspideo comunicando en forma directa el VI con AD.

- El cortocircuito se origina cercano al borde septal del anillo tricúspideo y tendrá una velocidad $>4 \mathrm{~m} / \mathrm{s}$ a diferencia del flujo de IT que se origina en la coaptación de la VT y es de menor velocidad.

- Si existe IT se deberá informar cual es el mecanismo y los detalles anatómicos de la valva septal.

\section{Bibliografía}

1. Muñoz Castellanos L, Martínez Asencio ME, Kuri Nivón M: Estudio morfopatológico de 101 corazones portadores de defecto septal interventricular. Arch Cardiol Mex 2005; 75: 393-401.

2. Saker E, Bahri GN, Montalbano MJ, Johal J, Graham RA, Tardieu G, et al.: Gerbode defect: A comprehensive review of its history, anatomy, embryology, pathophysiology, diagnosis, and treatment. J Saudi Heart Assoc 2017;29:283-292

3. Shi-Min Yuan. Left ventricle-to-right atrium shunt (Gerbode defect). Postep Kardiol Inter 2014;10,3(37):185-194. DOI: 10.5114/pwki.2014.45146. 